\title{
The evolution of embryonic creek systems in a recently inundated large open coast managed realignment site
}

Jonathan Dale, Heidi M. Burgess, Niall G. Burnside, Paul Kilkie, David J. Nash, and Andrew B. Cundy

\begin{abstract}
Managed realignment (MR) schemes are being implemented to compensate for the degradation of coastal habitats. However, evidence suggests that MR sites have lower biodiversity than anticipated, which has been linked to poor drainage. Despite creek networks playing an important role in enhancing site drainage in natural intertidal environments, there remains a shortage of data on the formation and evolution of creeks within MR sites. This study evaluates creek development at the Medmerry Managed Realignment Site, UK. Creek development is investigated using differential global positioning system (dGPS) data, supported by sedimentological analyses and a high-resolution digital surface model (DSM) derived from images taken using a small unmanned aerial vehicle. Measurements indicated that creeks will develop relatively quickly, but are influenced by differences in the sub-surface sedimentological conditions. A suitable level of agreement was found between the DSM and dGPS measurements, demonstrating the appropriateness of this method to study creek development within intertidal environments at a higher resolution than traditional surveying techniques. These results are used to propose the collapse of sub-surface piping as the primary creek formation mechanism. Findings are discussed in terms of increasing the success of MR schemes and enhancing site design to maximise the ecosystem services provided.
\end{abstract}

Key words: managed realignment, creeks, piping, small-unmanned aircraft system (sUAS), structure-from-motion (SfM).

\section{Introduction}

Tidal marsh systems are of global significance, occupying approximately 5.1 Mha of the Earth's surface (Pendleton et al. 2012). Only relatively recently, however, has the wider importance of these environments, in terms of the range of ecosystem services provided, been realised (Rotman et al. 2008). These services include protection from coastal flooding through wave attenuation, wildlife habitat, carbon sequestration, immobilisation of

\footnotetext{
Received 29 November 2017. Accepted 28 March 2018.

J. Dale, H.M. Burgess, N.G. Burnside, and P. Kilkie. Centre for Aquatic Environments, School of Environment and Technology, University of Brighton, Brighton BN2 4GJ, UK.

D.J. Nash. Centre for Aquatic Environments, School of Environment and Technology, University of Brighton, Brighton BN2 4GJ, UK; School of Geography, Archaeology and Environmental Studies, University of the Witwatersrand, Private Bag 3, Wits 2050, South Africa.

A.B. Cundy. National Oceanography Centre (Southampton), School of Ocean and Earth Science, University of Southampton, Southampton SO14 3ZH, UK.

Corresponding author: Jonathan Dale (e-mail: J.Dale2@brighton.ac.uk).

Copyright remains with the author(s) or their institution(s). This work is licensed under a Creative Commons Attribution 4.0 International License (CC BY 4.0), which permits unrestricted use, distribution, and reproduction in any medium, provided the original author(s) and source are credited.
} 
pollutants, and recreation opportunities (e.g., King and Lester 1995; Costanza et al. 1997; Moller et al. 2014). The recent recognition of these services comes within a context of the large-scale loss of tidal marshes in recent decades, through reclamation, drainage, and coastal squeeze (Doody 2004) or other erosional and degradative processes. These losses, along with concerns regarding the medium- to long-term integrity of coastal flood defences (French 2006), has resulted in a shift in the approach to coastal management used by engineers and policy makers, changing to techniques that recognise the importance of tidal marsh and mudflat systems for coastal protection and ecosystem functioning. Several restoration schemes to replace, or compensate for the loss of, the structural or functional characteristics of degraded, reclaimed or eroded tidal marsh habitat have been implemented, including replanting schemes or decreasing current velocities using offshore breakwaters to allow vegetation to become rooted and established (Doody 2008). This paper focuses on the most popular of these techniques (in Europe and America), managed realignment (MR): the process of shifting the land-sea border, usually by de-embanking defences and constructing new defences inland (French 2006).

Despite being designed to compensate for intertidal habitat loss, there is growing evidence that many MR sites have lower biodiversity and therefore delivery of ecosystem services than expected (e.g., Mazik et al. 2010; Mossman et al. 2012). This may be due to poor sub-surface hydrological connectivity and differences in drainage pathways within MR sites (Tempest et al. 2015), caused by disturbances and former land use practices impacting on the sediment structure (Spencer et al. 2017). Even though it has been recognised that poor sediment drainage, and anoxia caused by stagnant water, may be the cause of poor species diversity in MR sites (Mossman et al. 2012), there remains a lack of understanding of the geotechnical, morphological, and sedimentary processes within MR schemes (Esteves 2013). Tidal creeks may play an important role in the evolution and development of MR sites; in natural tidal marsh and mudflat environments creeks help to regulate site drainage, and become more effective at increasing drainage and tidal (and sediment) exchange as they develop (e.g., Symonds and Collins 2007).

In natural marsh systems, creeks form predominantly due to the intertidal environment being inefficient at draining water as the tide ebbs. Sheet flow becomes concentrated or dissipated by subtle variations in surface topography, creating a depression. Once formed, flow becomes focused within the area of the depression resulting in larger bed shear stresses and increased erosion (Whitehouse et al. 2000). The formation and evolution of creek networks has commonly been associated with the morphological and ecological evolution of the surrounding intertidal zone (e.g., Kirwan and Murray 2007). Models of initial creek formation usually consider rapid morphological development (e.g., D’Alpaos et al. 2005). In the long term (10-100 years), the rate of accretion slows and channels start to infill, as a result of a lowering in the discharge due to accretion on the surrounding intertidal platform (e.g., Marani et al. 2002; D’Alpaos et al. 2006).

Whilst advances have been made in understanding the development of creek networks in intertidal settings (e.g., Allen 2000; D'Alpaos et al. 2005; Kirwan and Murray 2007), there are relatively few empirical field studies of the initial formation of creek and drainage features in intertidal environments (Vandenbruwaene et al. 2012); the majority of data on initial creek evolution and development come from numerical morphodynamic models, probably due to most intertidal creek networks already being in a state of quasi-equilibrium (e.g., Marani et al. 2003). MR sites could, therefore, provide an opportunity to study creek formation and development in a previously non-channelled environment. Currently, little is known of the formation and development of creek-drainage networks in MR sites, with the majority of previous studies focusing on creek evolution outside of the realignment area following site breaching (e.g., Symonds and Collins 2007; Friess et al. 2014). The development of tidal creeks 
networks in MR sites has been suggested to be related to the features of the pre-existing landscape (French and Stoddart 1992), including the presence of drainage channels and surface features, such as plough lines (Spencer and Harvey 2012). The timescale for embryonic creek network development is also influenced by sediment properties (including the drainage characteristics), tidal energy, and the surface gradient of the intertidal zone (Cornu and Sadro 2002; Crooks et al. 2002; D'Alpaos et al. 2007; Spencer and Harvey 2012). Consequently, the drainage networks that develop in MR sites can vary considerably between sites, with any pre-existing terrestrial drainage systems being retained for many years and, in some cases, remaining as permanent features (e.g., Bowron et al. 2011). D’Alpaos et al. (2007) investigated drainage network density, comparing field data to modelled results, for a constructed saltmarsh in Venice Lagoon (Italy), whilst Williams et al. (2002) monitored channel cross-sectional areas in San Francisco Bay (United States) over a 13 year period. Both of these studies, however, have relatively low ( $>2$ year) temporal resolution. A high resolution empirical insight into creek formation in MR sites was provided by Vandenbruwaene et al. (2012), although for a controlled reduced tidal scheme on the Scheldt estuary (Belgium) where tidal inundation is reduced and controlled using sluice gates. The extent to which the findings of Vandenbruwaene et al. (2012) are relevant, and applicable, to sites where tidal inundation is not controlled and which are subject to natural tidal variability remains unclear.

This study aims to investigate the evolution of creek networks within a recently breached open coast MR site at Medmerry, West Sussex, UK (Fig. 1). The Medmerry Managed Realignment Site is the largest open coast MR scheme in Europe (at the time of site breaching), occupying $4.5 \mathrm{~km}^{2}$. Specifically, we utilise an innovative combination of datasets including surface sediment characteristics, and differential global positioning system (dGPS) measurements of the variation in embryonic central creek position and bed elevation, with a high resolution digital surface model (DSM) produced via structure-frommotion (SfM) analysis of images taken using a small-unmanned aircraft system (sUAS). Measurements are assessed to gain field-based knowledge on the formation and evolution of embryonic creek systems in a recently inundated intertidal environment, and to assess the suitability of using SfM analysis to examine creek development processes within these settings. We conclude with a consideration of the implications of our results for future MR site design.

\section{Materials and methods}

\section{Study site}

Located on the south coast of the UK (Fig. 1a), in the eastern Solent, the Medmerry Managed Realignment site was constructed due to concerns over the effectiveness of the former coastal flood defences, which consisted of a shingle barrier beach managed by the UK Environment Agency. The shingle bank required constant re-profiling during the winter to maintain the necessary defence standard to protect the coastal hinterland (Cope 2004). The Pagham to East Head Coastal Defence Strategy (Environment Agency 2007) concluded that, beyond the short-term, the existing defences were unable to prevent flooding, and endorsed MR as the most suitable method of managing the risk from coastal flooding.

In addition to its role as a flood defence scheme, the Medmerry site was also designed to compensate for tidal marsh and mudflat habitat loss elsewhere in the Solent. Over $80 \%$ of the coastline in this region is designated for its nature conservation interests (Foster et al. 2014). However, $40 \%$ of the Solent's saltmarsh (about $670 \mathrm{ha}$ ) were lost due to erosion between 1971 and 2001 (Cope et al. 2008). Over the 100 years following breaching at Medmerry, it is predicted that almost 184 ha of new intertidal habitat will be created within the site (Pearce et al. 2012). 
Fig. 1. (a) The Medmerry Managed Realignment Site, the location of the study site in the Medmerry site, and the United Kingdom and regional setting (insets) (background data @ Crown Copyright and Database Right 2017. Ordnance Survey (Digimap Licence)). (b) Orthomosiac aerial image of the study site, captured on 13 July 2016 by a small-unmanned aircraft system (sUAS), including the edge of the borrow pit (dotted line) and the area where creeks have developed (dashed square). See text for further discussion.
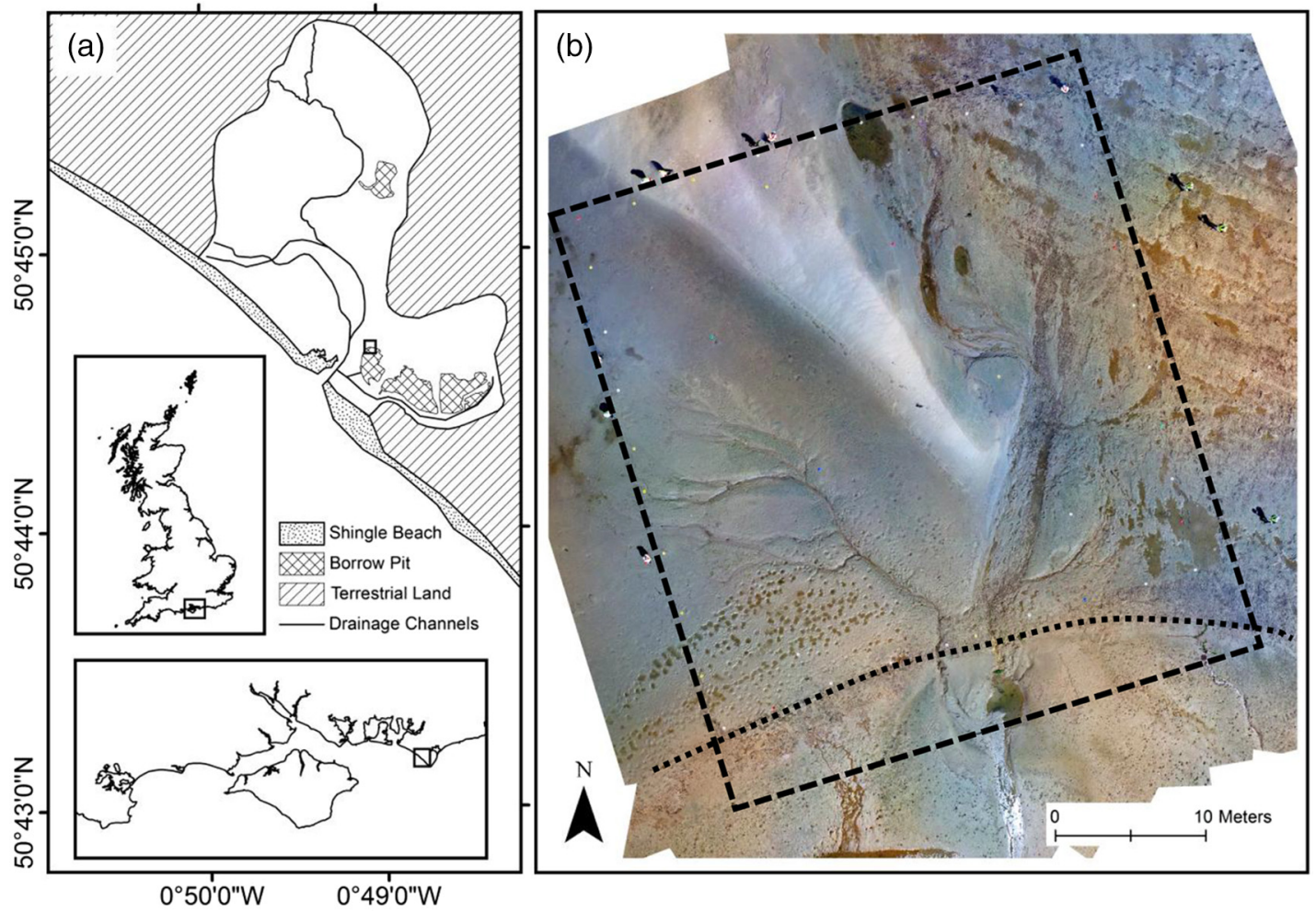

The Medmerry site consists of $7 \mathrm{~km}$ of new defences, reaching $3 \mathrm{~km}$ inland. Site design included areas of lower elevation (borrow pits) designed to encourage a range of (low elevation) intertidal habitat, where material was excavated and used to create the new flood defences, and a series of drainage networks consisting of pre-existing terrestrial channels (known locally as rifes) and steep-sided channels engineered during site construction. The shingle barrier beach was breached on 9 September 2013, forming a semi-diurnal, mesotidal estuarine system.

For this study, measurements were taken from the bank of a near-breach former barley field (Fig. 1b), in front of an infilling borrow pit (Dale et al. 2017), named Site 5 by Burgess et al. (2016), where embryonic creeks had developed following site breaching. This site was selected as it allowed for analysis of creek development in a rapidly evolving nearbreach environment. Tidal data, reported by Dale et al. (2017), indicated that the bank would typically be inundated for $2.5 \mathrm{~h}$ by approximately $0.70 \mathrm{~m}$ (spring tides) and $0.30 \mathrm{~m}$ (neap tides) of water per tidal cycle (Fig. 2).

\section{Sediment analysis}

The morphological development of the study site was assessed between July 2015 and June 2016 (i.e., 2-3 years after site breaching). Sediment samples were taken regularly (monthly) from the same location on the bank at low water, within $10 \mathrm{~m}$ of where 
Fig. 2. Tidal data, previously reported by Dale et al. (2017), for typical (a) spring tides on 5 August 2015 and (b) neap tides on 11 August 2015. The dashed line represents the elevation of the bank at the edge of the borrow pit (see text for description).
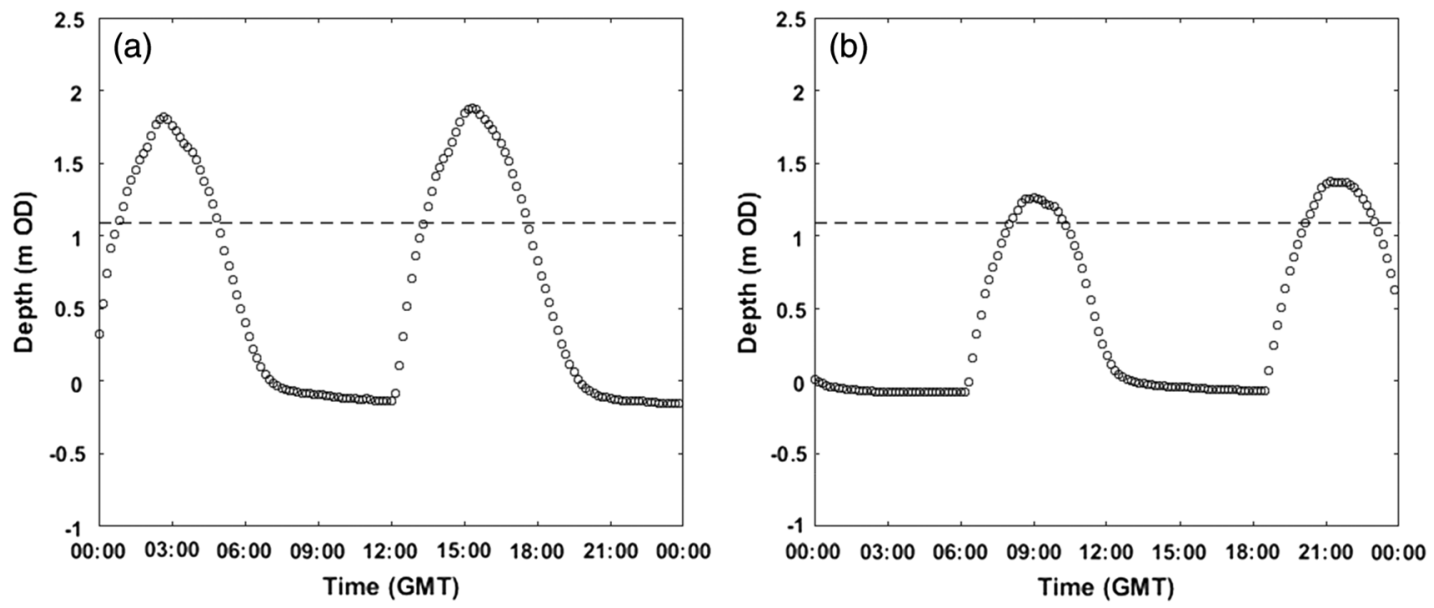

embryonic creeks had formed, to assess changes in physical characteristics as the site developed following tidal inundation. Samples were analysed using standard sedimentological procedures. The moisture content was measured as a percentage of the dry mass (water content $=$ wet sediment weight/dry sediment weight $\times 100$ ) after samples had been oven dried at $105{ }^{\circ} \mathrm{C}$ for $48 \mathrm{~h}$. The organic content of the samples was estimated via a proxy method, using a $6 \mathrm{~h}$ loss on ignition test at $450^{\circ} \mathrm{C}$. A Malvern Instruments Mastersizer Hydro 2000G Laser Diffraction Particle Size Analyser was used to determine both the grain size distribution and mud (clay + silt) content following hydrogen peroxide treatment to remove organic matter (which may bind the sediment and result in an underestimation of the clay fraction) and dispersion with sodium hexametaphosphate.

\section{Creek evolution measurements}

Position and elevation measurements were taken of developing creek networks using a dGPS on four occasions; 8 August 2015, 22 October 2015, 3 March 2016, and 10 June 2016. Measurements were taken of the creek position, from the centre of the creek, from within the borrow pit to the abrupt break in the longitudinal profile, known as the nickpoint, which usually characterises low-order creek networks (Symonds and Collins 2007). Positional data were supported by dGPS elevation data taken along three perpendicular (cross-profile) transects crossing the creek networks at the edge of the borrow pit (T1), inland (T2) and at the top of the embryonic system (T3), to evaluate changes in the width and depth of the creeks over time. Positional and elevation data were taken using a Leica AS19 GNSS antenna, a Leica Viva GS10 GPS receiver and a Leica CS15 controller. Raw GPS measurements were imported into Leica Geo Office (version 8.3). Network Receiver Independent Exchange Format (RINEX) correction data were obtained from Leica Smart Net UK \& Ireland (http://uk.smartnet-eu.com/ rinex-download_148.htm), with the correction applied to the raw data by the Leica software. Leica Geo Office reported the positional quality (XYZ) for all dGPS points as $<0.02 \mathrm{~m}$. All data were projected using the OSGB1936 coordinate system and datum.

\section{DSM}

Measurements taken using dGPS are subjective (in terms of measurement location) and are spatially limited, and therefore may not be the most appropriate method of measuring 
morphological development within complex intertidal environments, especially in terms of recording important sub-metre-scale spatial variations and morphological characteristics. sUAS are being used increasingly across a number of scientific disciplines as an alternative approach to provide high-resolution detailed imagery (e.g., James and Robson 2014; Tonkin and Midgley 2016; Strong et al. 2017). Images can be used for rapid reconstruction of surface geometry, providing there is sufficient overlap between images, without the need for camera position or orientation data through automated photogrammetric techniques (e.g., James and Robson 2012; Westoby et al. 2012; Javemick et al. 2014; Nolan et al. 2015). The emerging, low-cost photogrammetric method SfM with Multi-View Stereopsis provides a rapid method for high resolution topographic reconstruction (Westoby et al. 2012). SfM approaches have already been used to successfully assess geomorphological processes such as gully erosion (e.g., Castillo et al. 2012).

Aerial images were acquired at the Medmerry site on 13 July 2016 using a DJI Inspire 1 sUAS. The sUAS was flown at a target altitude of $20 \mathrm{~m}$ above ground level and at $5 \mathrm{~m}$ line spacing in consistent weather conditions (temperature, $18^{\circ} \mathrm{C}$; wind speed, $9 \mathrm{mph}(14 \mathrm{~km} / \mathrm{h}) \mathrm{NW}$; sun with minor cloud cover). Following an initial test flight, aerial images were acquired during four separate flights over an hour-long period using a crosshatched flight plan to ensure maximum overlap ( $>80 \%$ ) and a complete coverage of the study site. Images were captured using a DJI Zenmuse X3, 3-band RGB camera with a focal length of $20 \mathrm{~mm}$.

Seven ground control points were recorded using the dGPS system. Fisheye correction and camera alignment optimisation were applied to minimise the central "doming" effect reported in previous studies (e.g., James and Robson 2014), and potentially amplified due to the low flight height. A dense point cloud was produced from optimised camera locations, using mild-depth filtering to ensure the preservation of small and important detail. The dense point cloud output was used to generate both the orthomosaic image (Fig. 1b) and the DSM.

Independent assessment of the sUAS modelling was completed using an additional six control points, recorded using dGPS, to assess vertical and horizontal error of the DSM. To assess the effectiveness of the model as a tool for evaluating embryonic creek development, a further 54 dGPS positional measurements of the embryonic creek systems were captured, along with 53 elevation measurements from the three cross-profile transects. Root-meansquare-error (RMSE) and mean-absolute error (MAE) were calculated to validate the DSM against six independent control points, and as a measure of quality in comparison to the elevation measurements taken in the transects. Creek position dGPS data were compared visually to the DSM. All analysis was conducted using ArcGIS 10.2.2.

\section{Results}

\section{Surface sediment properties}

Moisture content ranged between $39 \%$ and $50 \%$ and showed little change as the creek systems developed. Loss on ignition increased slightly, ranging between $3.8 \%$ and 5.4\% (Fig. 3). Grain size was relatively coarse, with increased concentrations of fine-grained sediment during the summer. This is probably due to reduced inputs of sandy sediment as a result of more quiescent conditions and therefore less erosion of the relict hedgerows surrounding the site (recognised by Dale et al. (2017) to be the source of coarse-grained sediment to this site). Analysis of the sediment in the creek beds, sampled in July 2016 and analysed using the same procedure as the surface samples, indicates they developed on top of a less organic layer (loss on ignition, $2.80 \%$ ) with a higher concentration of fine-grained sediment $\left(d_{50}=22.50 \mu \mathrm{m}\right.$; mud content, $\left.54.59 \%\right)$ compared to the surrounding bank. This lower sediment unit is probably the former terrestrial surface, matching the observations of Tempest et al. (2015) from the Orplands Farm Managed Realignment Site (Essex, UK). 
Fig. 3. Change in sediment moisture content $(n=5)$, loss on ignition $(n=5)$, median grain size $\left(d_{50}\right)(n=3)$, and grain size distribution (clay, grey dashed line; silt, grey dashed-dotted line; sand, grey dotted line; mud (clay + silt), solid black line; $n=3$ ) during the study period. Vertical dashed lines represent when measurements of the position and elevation of the embryonic creeks were taken.
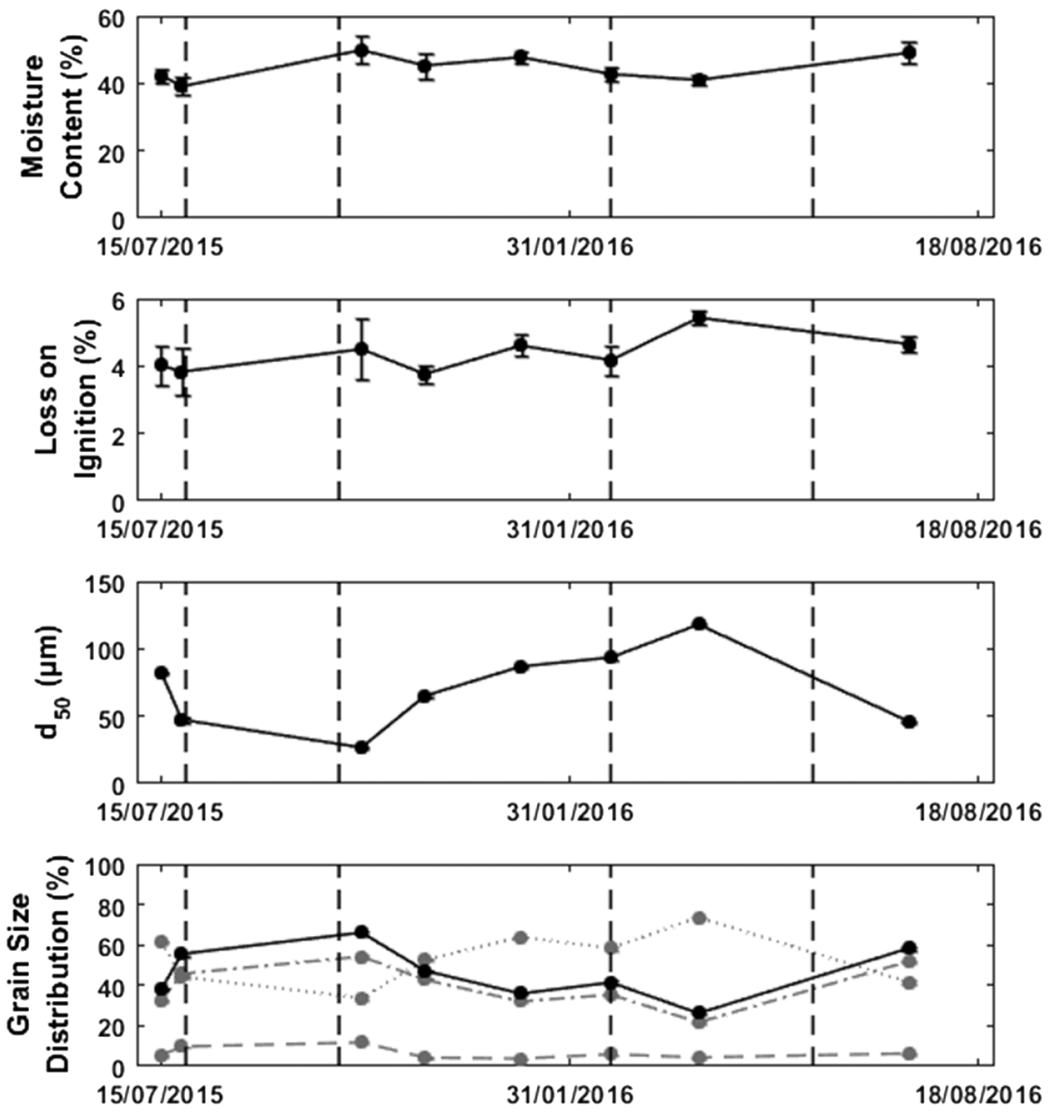

The embryonic creek systems

Two embryonic creek networks developed on the bank over the course of the monitoring period (as shown in Fig. 4). Overall, the eastern creek increased in length by $19.70 \mathrm{~m}$ during the measurement period. However, minimal landward erosion occurred in the eastern creek network following the second survey in October 2015, with the creek length increasing from 38.37 to $42.73 \mathrm{~m}$ during this period. The western creek continued to develop multiple branches and networks, although the length of the main channel only increased by $4.22 \mathrm{~m}$ during the measurement period. Elevation measurements taken in west-east cross section (see Fig. 4 for locations) demonstrate that around the edge of the borrow pit, T1, the position of the western creek remained relatively constant over time, with the elevation of the bed increasing by $15 \mathrm{~cm}$ and sediment accreting on the banks (Fig. $5 a$ ). In contrast, the elevation of the eastern creek fluctuated at the edge of the borrow pit, initially eroding by $8 \mathrm{~cm}$ (August to October 2015) then increasing in elevation by $10 \mathrm{~cm}$ (October 2015 - June 2016) with the channel migrating in a westerly direction.

Inland, across the middle transect T2, the position of the western creek network fluctuated and varied in depth and width, although the elevation of the creek bed increased by $13 \mathrm{~cm}$ during the study period (Fig. 5b). In the most recent survey (June 2016), a decrease 
Fig. 4. dGPS measurements of the position of the embryonic creek networks at the Medmerry Managed Realignment Site on (a) 8 August 2015, (b) 22 October 2015, (c) 3 March 2016, and (d) 10 June 2016. Measurements were taken from within the borrow pit to the nickpoint; the abrupt break in the longitudinal profile. Positions of cross-profile transects (T1, T2, and T3) are marked by dashed lines (see Fig. 5).
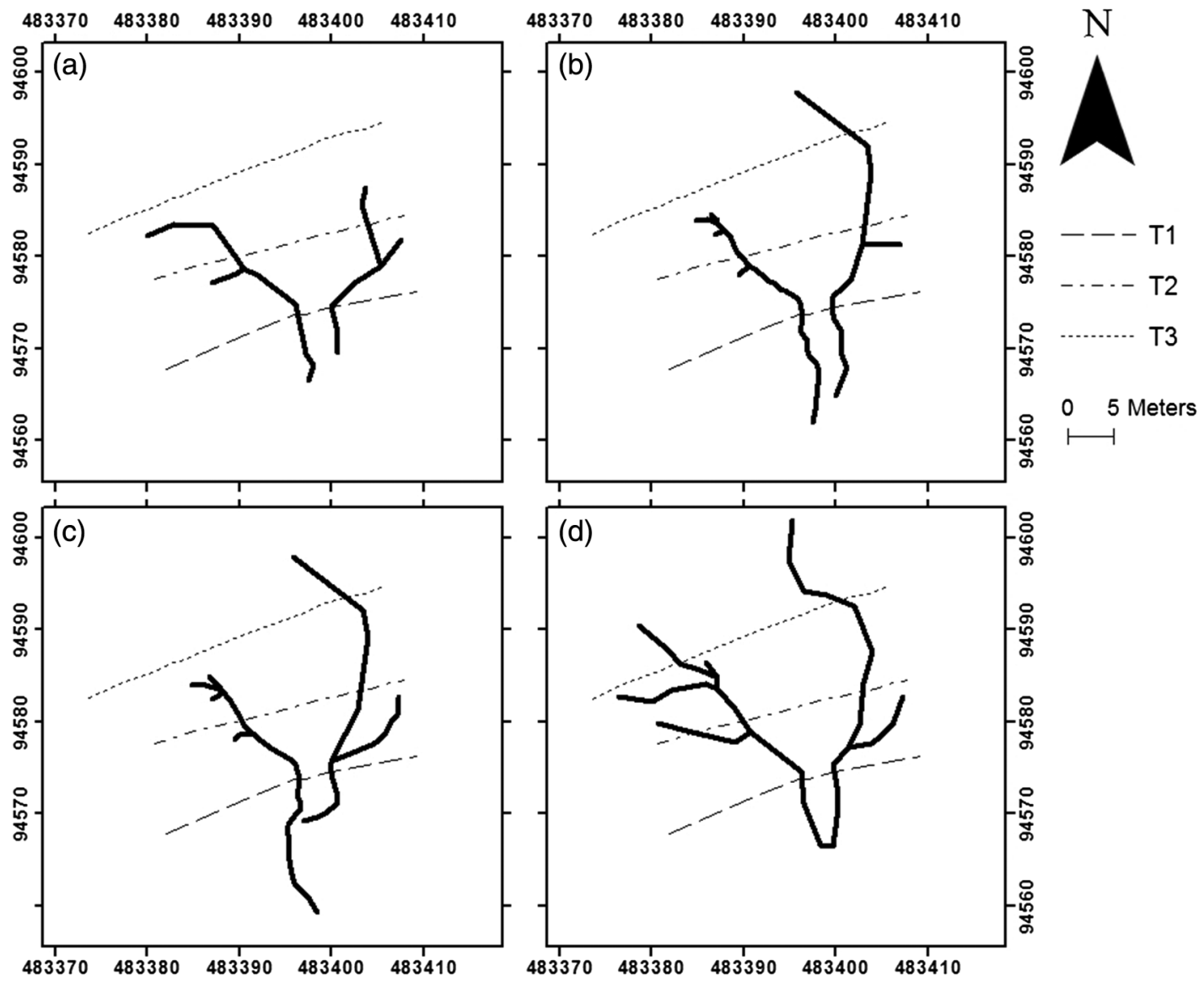

in elevation to the west of the main network was detected due to the headward erosion of a sub-channel (Fig. 4d). The depth of the eastern creek network increased across the middle transect by $12 \mathrm{~cm}$ between the first and third surveys, before decreasing between the third and final survey, with channel incision creating a broader channel, and accretion occurring on the surrounding banks.

At T3, the landwards extremity of the developing creek network (Fig. 5c), the eastern creek bed eroded by $8 \mathrm{~cm}$ and incised significantly over time, resulting in a wide channel with steep banks. The western channel, which had only extended headward to intersect transect T3 in the most recent survey, was not detected in elevation measurements.

\section{sUAS-derived DSM}

The sUAS survey, on 13 July 2016, acquired 319 images, which were used to produce a dense point cloud comprised of 4904206 matched points. The effective overlap of photographs was $>9$ images per point within the study area. The DSM (Fig. 6) had a reported resolution of $0.0263 \mathrm{~m}$ per pixel, and the resolution of the RGB orthorectified image (Fig. 1b) was $0.00658 \mathrm{~m}$ per pixel. The software reported a total RMSE value of $0.027 \mathrm{~m}$ for the final 
Fig. 5. Elevation changes across the bank taken from $(a) \mathrm{T} 1$ at the edge of the borrow pit, $(b) \mathrm{T} 2$ inland, and $(c) \mathrm{T} 3$ at the top of the embryonic creek system on 8 August 2015, 22 October 2015, 3 March 2016, and 10 June 2016 (see Fig. 4 for location). The reported error in all elevation measurements was $< \pm 0.02 \mathrm{~m}$.
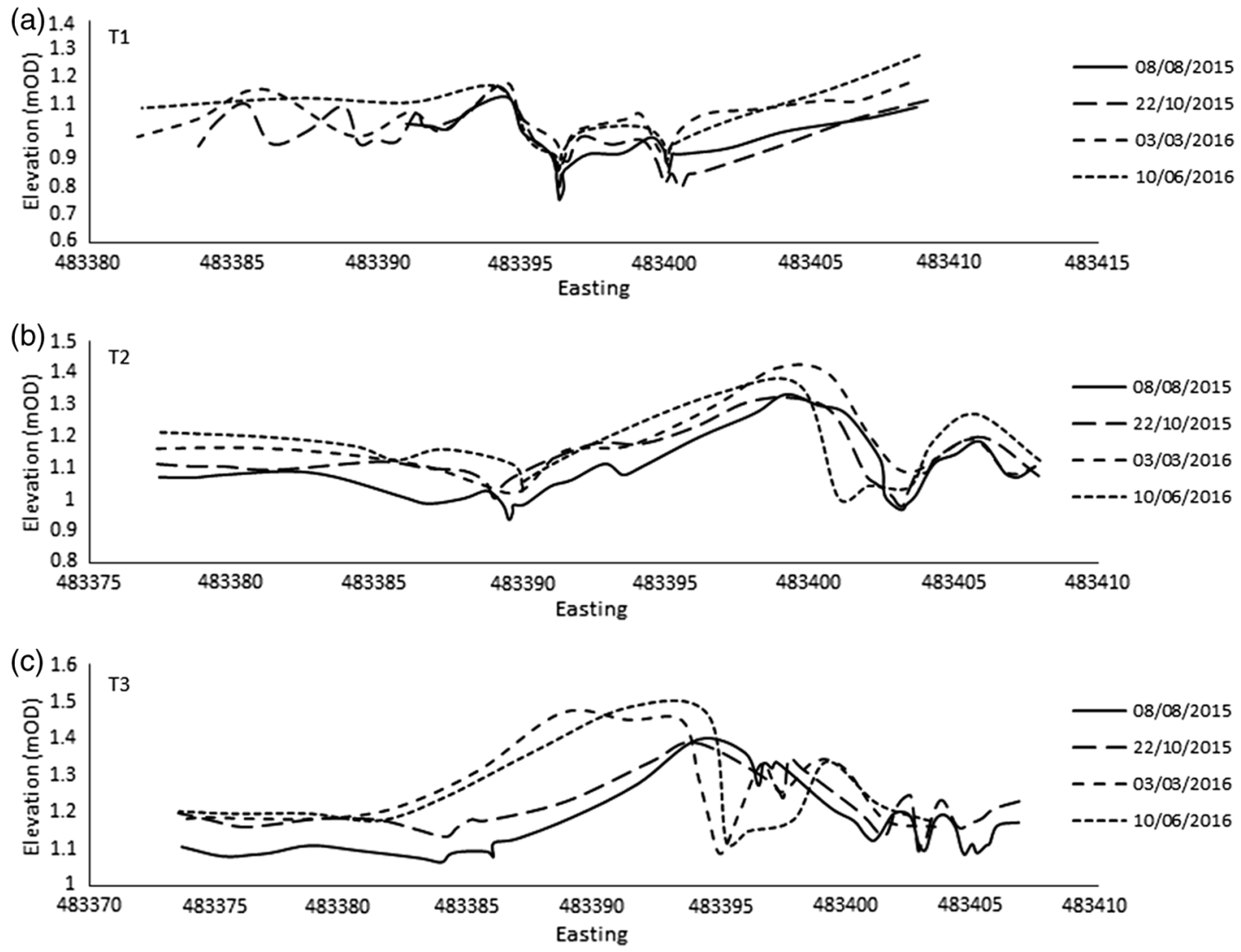

orthophoto (Agisoft 2016). Independent comparisons between the DSM and the six dGPS measured control points (Table 1) indicated that the difference in position (XY) ranged between 0.017 and $-0.058 \mathrm{~m}$ (DSM minus dGPS measurements), with RMSE values of 0.028 and $0.033 \mathrm{~m}$ for the $x$ and $y$ values, respectively. Vertical differences between the independent control points and the DSM varied between 0.022 and $-0.038 \mathrm{~m}$. The RMSE value was $0.024 \mathrm{~m}$ and the MAE was $0.023 \mathrm{~m}$, within the range of acceptable values for reasonable surface reconstruction reported by Tonkin and Midgley (2016). A visual comparison (Fig. 6) indicated that the DSM closely resembled the dGPS measurements of creek position. The vertical RMSE between the DSM and dGPS transect measurements was $0.032 \mathrm{~m}$ and the MAE was $0.025 \mathrm{~m}$, ranging from 0.085 to $-0.056 \mathrm{~m}$ (Table 1), indicating a high degree of confidence in the ability of the sUAS-derived DSM to represent the developing morphological features in newly inundated intertidal settings.

\section{Discussion}

\section{Embryonic creek evolution}

Within the Medmerry Managed Realignment Site, two embryonic creek networks have formed on the bank surrounding a near-breach infilling borrow pit, extending $28 \mathrm{~m}$ inland (i.e., away from the borrow pit, Fig. 4). As the creeks have formed, the elevation of the bank 
Fig. 6. DSM produced of the study site, with the position of the six independent control points, the creek positions measured by a dGPS, and the location of sampling points taken in three W-E transects across the study area (see Figs. 4 and 5), indicated.

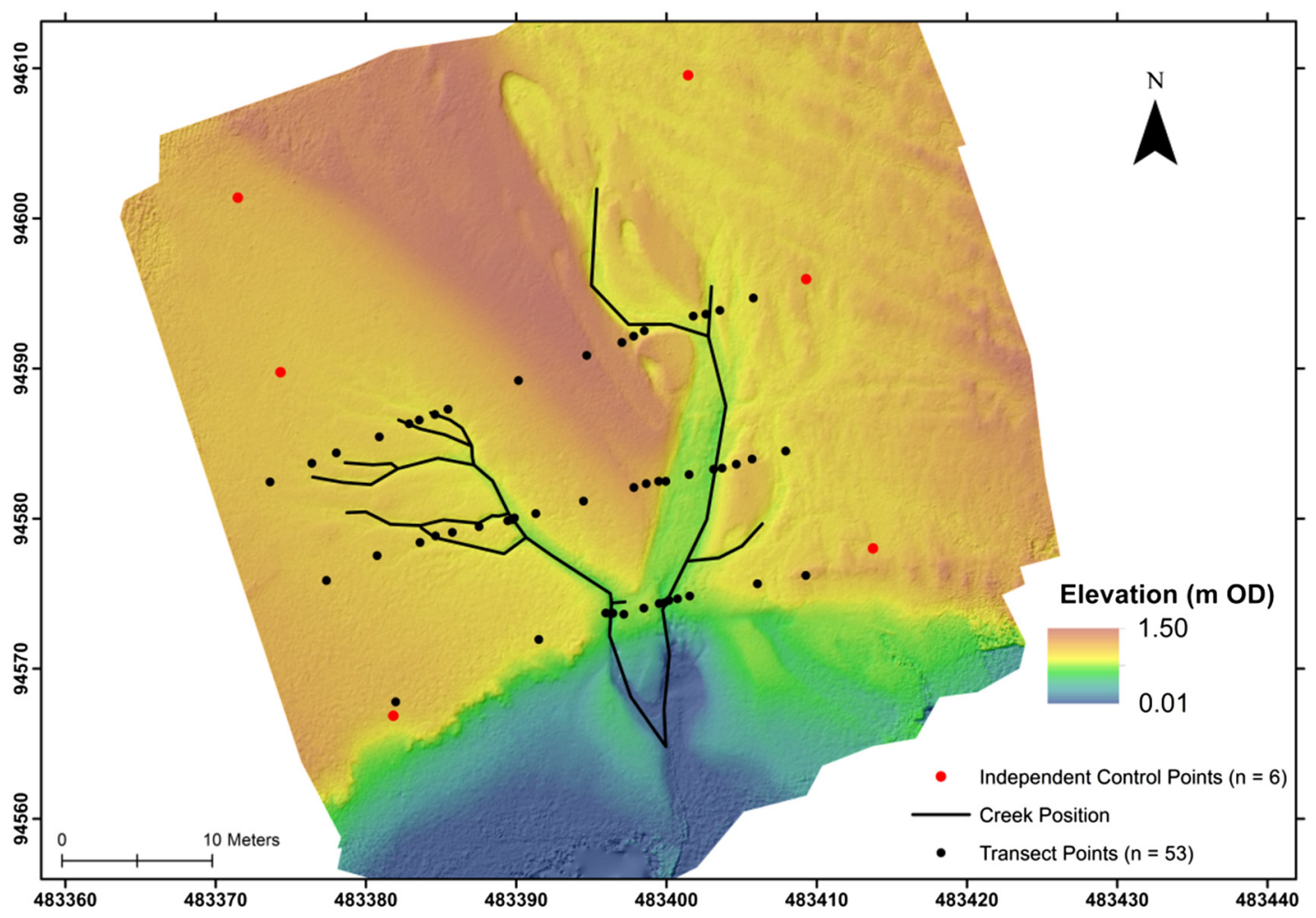

Table 1. DSM quality in comparison to $x, y$, and vertical dGPS measurements of six independent control points and the vertical measurements from 53 measurements taken from three transects crossing the study area.

\begin{tabular}{|c|c|c|c|c|}
\hline & \multicolumn{3}{|c|}{ Independent control points } & \multirow{2}{*}{$\begin{array}{l}\text { Transects } \\
\text { (vertical) }\end{array}$} \\
\hline & $x$ & $y$ & Vertical & \\
\hline Mean difference (m) & -0.016 & -0.021 & -0.012 & 0.009 \\
\hline Maximum difference (m) & 0.017 & 0.006 & 0.022 & 0.085 \\
\hline Minimum difference (m) & -0.057 & -0.058 & -0.038 & -0.056 \\
\hline $\operatorname{RMSE}(\mathrm{m})$ & 0.028 & 0.033 & 0.024 & 0.032 \\
\hline MAE (m) & 0.023 & 0.024 & 0.023 & 0.025 \\
\hline
\end{tabular}

has increased rapidly, with coarse inorganic sediment being deposited. In contrast, the change in bed elevation within the creeks has been considerably lower. The evolution of the creek networks does not appear to have influenced the physical surface sediment properties at the study site (Fig. 3), in terms of moisture content, loss on ignition, and grain size.

The formation and evolution of creek networks is generally considered to be caused by pre-existing topographic irregularities, which concentrate the flow and hence promote erosion (e.g., D'Alpaos et al. 2006). MR sites may provide the best opportunity to study these processes empirically in a previously non-channelled landscape (Vandenbruwaene et al. 2012), whereas in most intertidal marshes creeks have already formed and reached a state 
Fig. 7. Water flowing from the bottom of a pipe (inset) through the bank of the borrow pit in June 2014.

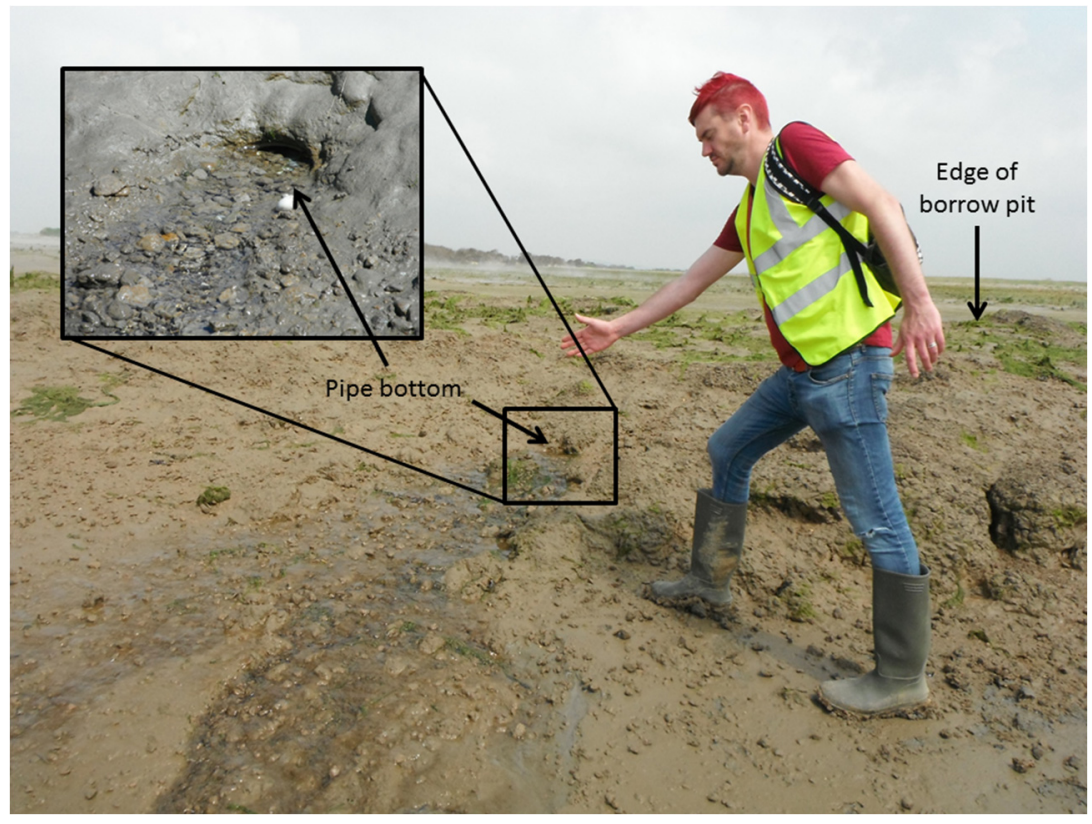

of quasi-equilibrium (Marani et al. 2003; Vandenbruwaene et al. 2012). From observations and measurements of creek formation at Medmerry made in this study, it is proposed that the creek networks formed due to the collapse of sub-surface tunnels, a phenomenon known as piping. Creeks have formed in areas where water appeared to be draining from the bank through sub-surface tunnels that emerged at the surface within the borrow pit (Fig. 7), first observed in June 2014, and which have subsequently collapsed. The occurrence of piping has commonly been documented in arid and semi-arid regions with occasional high intensity rainfall events (e.g., Gutierrez et al. 1997), and within the engineering literature regarding dam failure (e.g., Liu 2012), and was first observed in saltmarsh environments by Kesel and Smith (1978). To the authors' knowledge this is the first record of piping in a newly inundated intertidal setting.

Piping occurs when there is a sub-surface flow of water through pores, cracks, root channels, and other sub-surface (high permeability) features, which flushes out the fine sediment forming a pipe below the surface (Kesel and Smith 1978). In newly inundated former terrestrial sites, such as Medmerry, previously free draining sediments are exposed to tidal cyclicity following de-embankment and become saturated twice a day. As tidal waters recede faster than the soil can drain, a differential hydraulic head forms at the edges of the banks and main drainage features (channels and borrow pits). During periods of bank exposure (i.e., low water), water flows through the bank towards the lower hydraulic head due to the difference in hydrostatic pressure. The flow of water flushes fine sediments from the bank, increasing the diameter of the sub-surface pipe, with entrances forming at the top of the banks due to focussed surface collapse. Eventually the sub-surface pipes collapse along their length, forming embryonic creeks.

From the observations made at the Medmerry Managed Realignment Site, it remains unclear whether there is a common difference in head required to generate piping, and further analysis of other MR sites (and natural intertidal settings) is required to assess whether these processes are occurring elsewhere. However, the use of the sUAS orthophoto provides 
Fig. 8. Evidence of piping $(a)$ to the west and $(b)$ to the east of the embryonic creek networks at the Medmerry Managed Realignment Site.
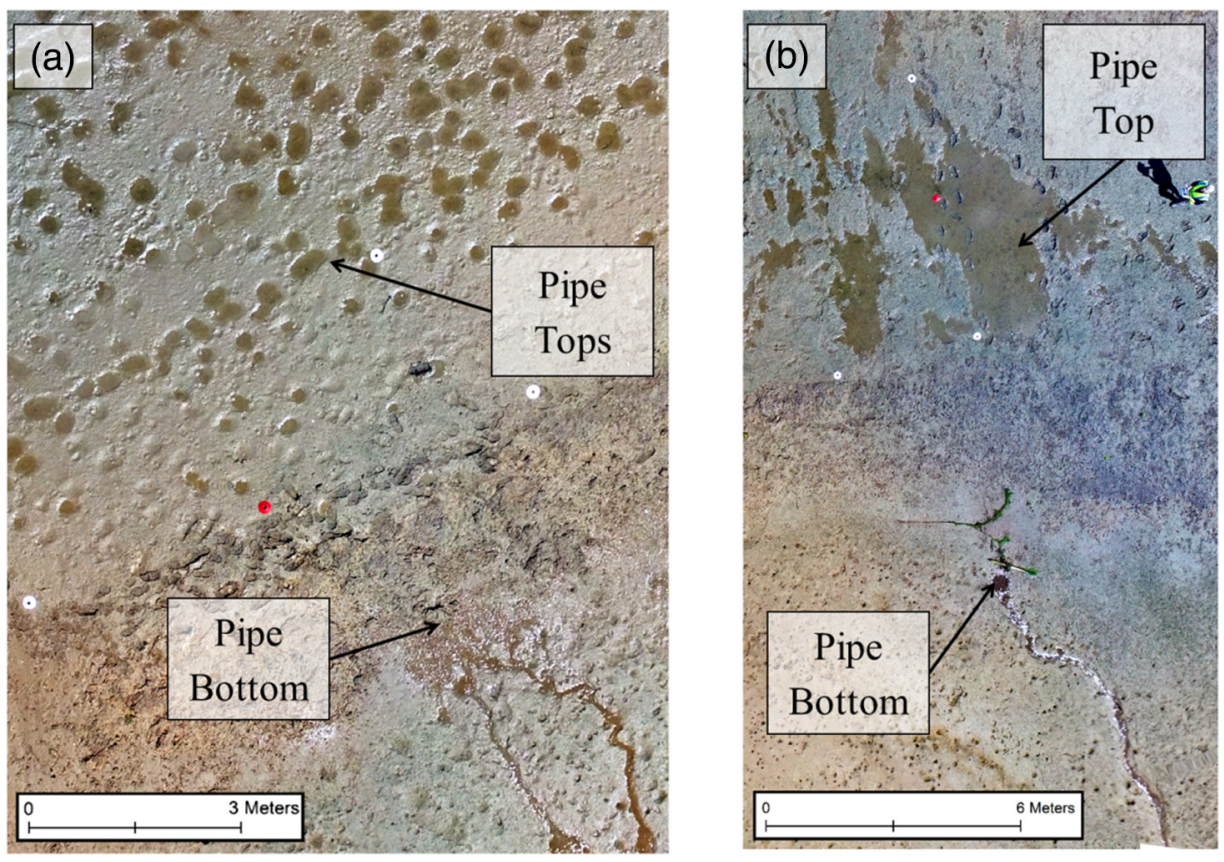

clear evidence for this process continuing to occur at this site 3 years after site breaching. From the orthomosaic produced, two locations can be identified where additional pipe networks appear to be emerging from the bank (Fig. 8) with areas of pooled percolating water identifiable on the bank; these have been verified visually on site. One of the systems, to the west of the embryonic creek networks (Fig. 8a), appears to be fed by a series of small pipe tops running parallel to the borrow pit edge, and emerges as a single outlet within the borrow pit. A larger, more irregularly shaped, pipe top feeds the second of these creek systems to the east of the creek network (Fig. 8b).

\section{The suitability of sUAS technology for measuring embryonic creek formation}

The use of sUAS-SfM surveys elsewhere (e.g., Westoby et al. 2012; Javemick et al. 2014) has successfully produced high-resolution models without the spatial limitations (i.e., interpolation from individual points) and user bias created by selectively choosing the measuring location associated with dGPS measurements. In addition, the data collection process for sUAS-SfM surveys takes the same amount of time as taking dGPS measurements, but at a much higher resolution $(<0.03 \mathrm{~m}$ resolution for the DSM in comparison to up to several metres between individual dGPS points). A comparison of the three transects analysed in this study (Fig. 9), measured by dGPS and extracted from the DSM, indicates that the dGPS readings are effective at measuring elevation at a centimetre to metre scale, but miss smaller topographic variations. This comparison also provides further confidence in the DSM given the similarity, in the majority of measurements, between the dGPS points and the modelled elevation.

Some discrepancies do exist between the DSM and dGPS measurements (Fig. 9), possibly caused by variability associated with the $x, y$ error or the influence of edge effects and the parameters used in the DSM construction process. There is also the possibility that errors 
Fig. 9. Comparison of $(a)$ T1 at the edge of the borrow pit, (b) T2 inland, and (c) T3 at the top of the embryonic creek system from the DSM (solid black) and dGPS measurements (dashed grey) (see Fig. 4 for location).
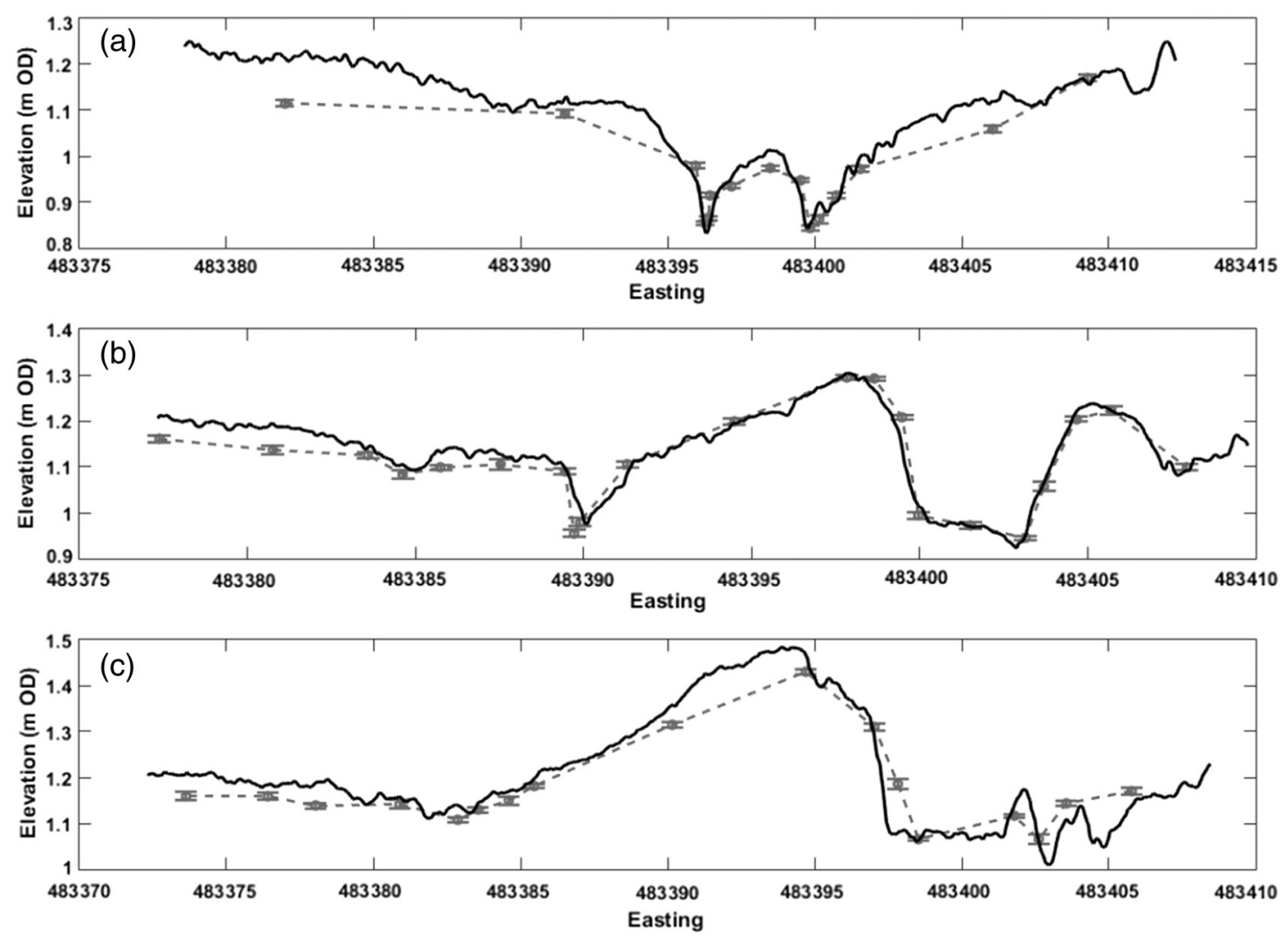

exist in the vertical measurements, caused by measuring the elevation using dGPS in relatively soft unconsolidated sediment. Nonetheless, the use of sUAS-SfM is likely to mitigate these errors as ground control points can be taken in more consolidated areas. Furthermore, through the use of separate control points in model construction and as an independent check, the quality of the model can be assessed; an option not available using just dGPS measurements. The DSM produced is also at a higher, more suitable, resolution than standard remote sensing techniques, such as LiDAR, which have previously been used in the design and prediction of ecological response to MR schemes (e.g., Blott and Pye 2004; Millard et al. 2013; Krolik-Root et al. 2015), increasing the likelihood that small (but important) changes in elevation will be captured. This technique could, therefore, be utilised to provide a more detailed understanding of how creek features develop within intertidal wetland environments.

While the dGPS surveys utilised in this study can be effectively used to monitor metrescale (and, in cross sections in Fig. 5, centimetrem-scale) changes in creek morphology, and show strong concordance with sUAS-SfM data (Fig. 6), repeated sUAS-SfM surveys of this nature would allow for the analysis of accurate volumetric changes across the site. This would then allow for the net changes in sediment accretion and erosion to be established on a spatial scale beyond the capabilities of methods currently being utilised in these environments (e.g., Ni et al. 2014; Dale et al. 2017), and in intertidal wetland environments generally. This technique may also allow for advanced and effective drainage network mapping considering changes pre- and post-site breaching, over the temporal and spatial scales 
Fig. 10. The two distinct sediment units in which creeks have formed consisting of the (lower) terrestrial sediment and (upper) sediment deposited following site breaching.

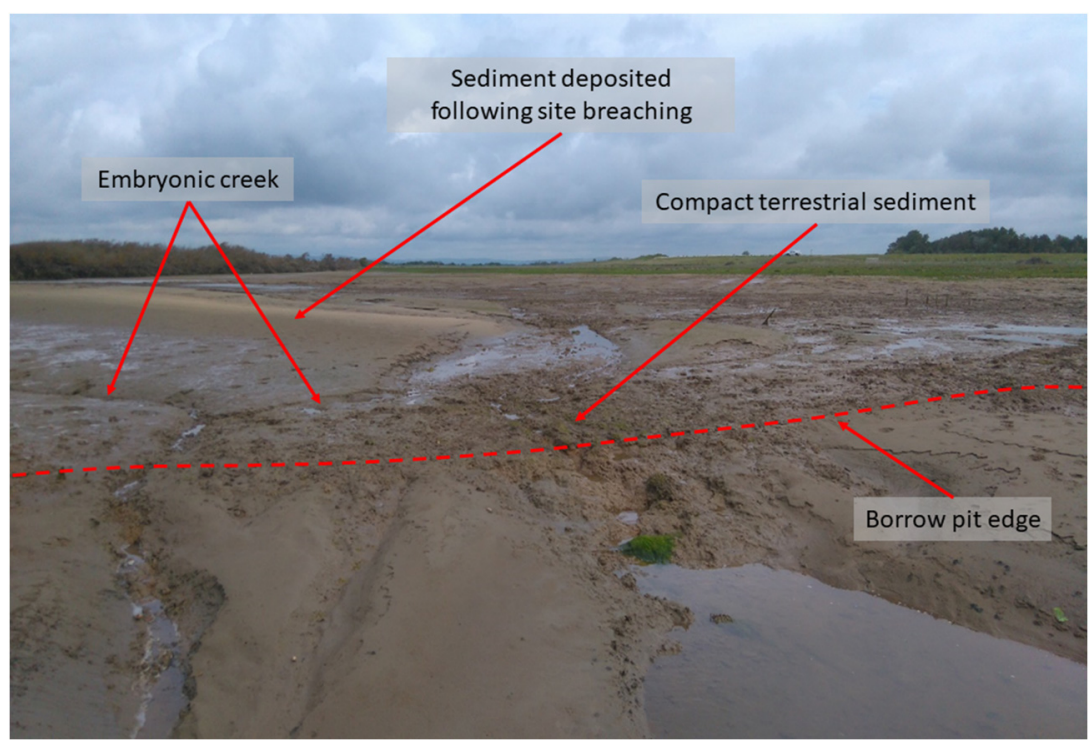

in which embryonic creek formation takes place, to inform coastal engineers and managers of the influence of different site design processes and the impact of any morphological features (e.g., borrow pits or terrestrial-constructed drainage channels) existing prior to site breaching. This would improve the design of MR sites, encouraging creek development, to enhance the success of future schemes.

\section{Influence of the former land use on creek formation and evolution}

Watts et al. (2003) proposed that creeks would only form in soft accreted sediments exceeding a critical depth of $20-30 \mathrm{~cm}$. There has been a large amount of accretion in the vicinity of the creek networks forming at this site; Dale et al. (2017) reported over $15 \mathrm{~cm}$ of accretion in the borrow pit adjacent to the area monitored here over a 1 year study period during the second year following site breaching. However, at Medmerry, creek formation was already occurring due to a difference in hydraulic head and sub-surface drainage, prior to the level of accretion reaching the critical $20-30 \mathrm{~cm}$ depth proposed, albeit site specifically, by Watts et al. (2003).

It was reported by Vandenbruwaene et al. (2012) that creek development was hindered by a compact clay layer in controlled reduced tidal schemes on the Scheldt (Belgium). Observations made at Medmerry suggest that a similar process is occurring. Following pipe collapse, creeks have not been able to incise through an underlying layer of finer-grained (seemingly more compact) sediment (Fig. 10), compared to the coarse-grained surface sediment. It is likely that this lower sediment unit is of terrestrial origin, suggesting that creek development is determined by the relationship between different sub-surface sediment conditions (and sediment types). It is widely considered that de-embankment should be carried out on areas previously reclaimed for agricultural use (French 2006); this inevitably means that most MR sites will have a complex sub-surface stratigraphy. Cundy et al. (2002), for example, found evidence that the terrestrial soil horizon could still be detected at Pagham harbour (southern UK) almost a 100 years after natural site breaching during a storm event, whilst Tempest et al. (2015) demonstrated that the former terrestrial horizon 
significantly restricted sub-surface hydrological connectivity at the Orplands Farm MR Site (Essex, UK).

Rapid creek development in MR sites is considered essential for site drainage, the evolution of the sediment regime, coastal flood defence, and the ecosystem services provided, although results in this study suggested that moisture content (indicative of sediment drainage) in surrounding surface sediments did not decrease as creeks developed. Given that the majority of MR sites are constructed on areas of the coastal hinterland that have been used for arable agriculture, it is likely that sediment has been compacted and structurally altered (Dent et al.1976). Consequently, there is a need for high rates of sediment accretion in MR sites to reduce the influence of the terrestrial sediment unit or to engineer sites to encourage creek development and growth. For example, sites could be ploughed or engineered to expose uncompacted soils that are more susceptible to creek formation, or dredged material could be distributed over the terrestrial soil prior to site breaching; D'Alpaos et al. (2007), for example, observed rapid creek evolution in a reconstructed saltmarsh in Venice Lagoon where dredged material had been used in site regeneration.

The design of drainage networks and borrow pits in MR sites could also be enhanced to encourage the drainage and formation of a differential hydraulic head to accelerate piping, and therefore creek development, as observed in this study. This could also incorporate preexisting drainage features, such as soakaways and drainage pipes; features that have received little consideration in the design of MR sites to date. Identification of the processes and analysis of the parameters influencing embryonic creek development within other MR sites is required to assess the similarity between sites. Sub-surface pipes are transient features, limiting the timeframe available for capturing their influence on embryonic creek development. Experimental laboratory or numerical modelling studies may, therefore, be necessary to analyse the influence of different sub-surface sedimentological conditions on creek formation in an intertidal setting, as have previously been carried out for alternative environments (e.g., Wang et al. 2016). This would improve the design of MR sites and encourage creek development following site breaching, thereby increasing the level of coastal flood defence, providing compensation for habitat losses and degradation, and enhancing the ecosystem services provided.

\section{Conclusion}

There is growing evidence that MR sites have lower biodiversity and delivery of ecosystem services than anticipated (e.g., Mossman et al. 2012), which has been associated with poor drainage and hydrological connectivity within these sites (e.g., Tempest et al. 2015). Despite intertidal creek networks being important for drainage (and indeed sediment supply), little is known about the evolution of embryonic creek networks in recently inundated intertidal environments. It has previously been suggested that creeks would only form providing there had been a sufficient level of sediment accretion (Watts et al. 2003). However, analysis of the sedimentological factors influencing creek formation at the Medmerry Managed Realignment Site, where it is proposed creeks have formed as a result of the collapse of sub-surface pipes, indicates that creeks will form in the inundated terrestrial sediment, although their subsequent incision and further development is limited. Given this, the use of dredged material and site landscaping to accelerate creek growth post-site breaching requires wider consideration. Using these measures to promote creek development will enhance the ecosystem services, habitat loss compensation, and level of coastal flood defence provided by MR sites.

Given the highly dynamic nature of these newly-inundated environments, frequent, and regular, site visits are required to make these observations, especially given the transient nature of embryonic creek formation processes. Measurements of embryonic creek growth 
indicate that creeks will develop relatively quickly but are influenced by sub-surface sedimentological conditions (such as sediment compaction and consolidation), which influence hydrological connectivity, and which in many cases will relate to historic environmental change and the former land use. Higher resolution measurements of embryonic creek growth are required to capture the onset of creek development and to provide further insight into the factors controlling creek evolution in newly inundated MR sites; the sUAS method discussed here would provide such measurements.

\section{Acknowledgements}

The authors would like to thank David Stansbury for his support with GPS measurements; Peter Hughes (RSPB); Magda Grove and Matt Leake (both University of Brighton) for their assistance with fieldwork; and Callum Firth for his guidance during JD and PK's studentship. We would also like to thank two anonymous reviewers for their supportive and constructive comments on an earlier version of the manuscript. Financial support was provided by the Environment Agency (UK) for JD's studentship and by the School of Environment and Technology, University of Brighton for PK's studentship.

\section{References}

Allen, J.R.L. 2000. Morphodynamics of Holocene salt marshes: A review sketch from the Atlantic and Southern North Sea coasts of Europe. Quat. Sci. Rev. 19: 1155-1231. doi: 10.1016/S0277-3791(99)00034-7.

Blott, S.J., and Pye, K. 2004. Application of lidar digital terrain modelling to predict intertidal habitat development at a managed retreat site: Abbotts Hall, Essex, UK. Earth Surf. Processes Landforms, 29: 893-905. doi: 10.1002/ esp.1082.

Bowron, T., Neatt, N., van Proosdij, D., Lundholm, J., and Graham, J. 2011. Macro-tidal salt marsh ecosystem response to culvert expansion. Restor. Ecol. 19: 307-322. doi: 10.1111/j.1526-100X.2009.00602.x.

Burgess, H., Kilkie, P., and Callaway, T. 2016. Understanding the physical processes occurring within a new coastal managed realignment site, Medmerry, Sussex, UK. In Coastal management: Changing coast, changing climate, changing minds. Edited by A. Baptiste. ICE Publishing, London, UK. pp. 263-272.

Castillo, C., Perez, R., James, M.R., Quinton, J.N., Taguas, E.V., and Gomez, J.A. 2012. Comparing the accuracy of several field methods for measuring gully erosion. Soil Sci. Soc. Am. J. 76: 1319-1332. doi: 10.2136/sssaj2011.0390.

Cope, S. 2004. Breaching of UK coarse-clastic barrier beach systems methods developed for predicting breach occurrence, stability and flooded hinterland evolution. Ph.D. thesis, University of Portsmouth, Portsmouth, UK.

Cope, S., Bradbury, A., and Gorczynska, M. 2008. Solent dynamic coast project: Main report; a tool for SMP2. New Forest District Council and the Channel Coastal Observatory, Southampton, UK.

Cornu, C.E., and Sadro, S. 2002. Physical and functional responses to experimental marsh surface elevation manipulation in Coos Bay's South Slough. Restor. Ecol. 10: 474-486. doi: 10.1046/j.1526-100X.2002.01035.X.

Costanza, R., d’Arge, R., deGroot, R., Farber, S., Grasso, M., Hannon, B., et al. 1997. The value of the world's ecosystem services and natural capital. Nature, 387: 253-260. doi: 10.1038/387253a0.

Crooks, S., Schutten, J., Sheern, G.D., Pye, K., and Davy, A.J. 2002. Drainage and elevation as factors in the restoration of salt marsh in Britain. Restor. Ecol. 10: 591-602. doi: 10.1046/j.1526-100X.2002.t01-1-02036.x.

Cundy, A.B., Long, A.J., Hill, C.T., Spencer, C., and Croudace, I.W. 2002. Sedimentary response of Pagham Harbour, southern England to barrier breaching in AD 1910. Geomorphology, 46: 163-176. doi: 10.1016/S0169-555X(02) 00060-0.

Dale, J., Burgess, H.M., and Cundy, A.B. 2017. Sedimentation rhythms and hydrodynamics in two engineered environments in an open coast managed realignment site. Mar. Geol. 383: 120-131. doi: 10.1016/j.margeo.2016.12.001.

D’Alpaos, A., Lanzoni, S., Marani, M., Fagherazzi, S., and Rinaldo, A. 2005. Tidal network ontogeny: Channel initiation and early development. J. Geophys. Res.: Earth Surf. 110: F02001. doi: 10.1029/2004JF000182.

D’Alpaos, A., Lanzoni, S., Mudd, S.M., and Fagherazzi, S. 2006. Modeling the influence of hydroperiod and vegetation on the cross-sectional formation of tidal channels. Estuar. Coast. Shelf Sci. 69: 311-324. doi: 10.1016/j. ecss.2006.05.002.

D’Alpaos, A., Lanzoni, S., Marani, M., Bonornetto, A., Cecconi, G., and Rinaldo, A. 2007. Spontaneous tidal network formation within a constructed salt marsh: Observations and morphodynamic modelling. Geomorphology, 91: 186-197. doi: 10.1016/j.geomorph.2007.04.013.

Dent, D.L., Downing, E.J.B., and Rogaar, H. 1976. Changes in the structure of marsh soils following drainage and arable cultivation. J. Soil Sci. 27: 250-265. doi: 10.1111/j.1365-2389.1976.tb01995.x.

Doody, J.P. 2004. 'Coastal squeeze' — An historical perspective. J. Coast. Conserv. 10: 129-138. doi: 10.1652/1400-0350 (2004)010[0129:CSAHP]2.0.CO;2.

Doody, J.P. 2008. Saltmarsh conservation, management and restoration. Springer, the Netherlands.

Environment Agency. 2007. Pagham to East Head draft coastal defence strategy. Environment Agency, Worthing, UK. 
Esteves, L.S. 2013. Is managed realignment a sustainable long-term coastal management approach? J. Coastal Res., Spec. Issue, 65: 933-938. doi: 10.2112/SI65-158.1.

Foster, N.M., Hudson, M.D., Bray, S., and Nicholls, R.J. 2014. Research, policy and practice for the conservation and sustainable use of intertidal mudflats and saltmarshes in the Solent from 1800 to 2016. Environ. Sci. Policy, 38: 59-71. doi: 10.1016/j.envsci.2013.10.013.

French, J.R., and Stoddart, D.R. 1992. Hydrodynamics of salt marsh creek systems: Implications for marsh morphological development and material exchange. Earth Surf. Processes Landforms, 17: 235-252. doi: 10.1002/ esp.3290170304.

French, P.W. 2006. Managed realignment - The developing story of a comparatively new approach to soft engineering. Estuar. Coast. Shelf Sci. 67: 409-423. doi: 10.1016/j.ecss.2005.11.035.

Friess, D.A., Möller, I., Spencer, T., Smith, G.M., Thomson, A.G., and Hill, R.A. 2014. Coastal saltmarsh managed realignment drives rapid breach inlet and external creek evolution, Freiston Shore (UK). Geomorphology, 208: 22-33. doi: 10.1016/j.geomorph.2013.11.010.

Gutierrez, M., Sancho, C., Benito, G., Sirvent, J., and Desir, G. 1997. Quantitative study of piping processes in badland areas of the Ebro Basin, NE Spain. Geomorphology, 20: 237-253. doi: 10.1016/S0169-555X(97)00026-3.

James, M.R., and Robson, S. 2012. Straightforward reconstruction of 3D surfaces and topography with a camera: Accuracy and geoscience application. J. Geophys. Res.: Earth Surf. 117: F03017. doi: 10.1029/2011JF002289.

James, M.R., and Robson, S. 2014. Mitigating systematic error in topographic models derived from UAV and groundbased image networks. Earth Surf. Processes Landforms, 39: 1413-1420. doi: 10.1002/esp.3609.

Javemick, L., Brasington, J., and Caruso, B. 2014. Modeling the topography of shallow braided rivers using Structurefrom-Motion photogrammetry. Geomorphology, 213: 166-182. doi: 10.1016/j.geomorph.2014.01.006.

Kesel, R.H., and Smith, J.S. 1978. Tidal creek and pan formation in intertidal salt marshes, Nigg Bay, Scotland. Scot. Geogr. Mag. 94: 159-168. doi: 10.1080/00369227808736403.

King, S.E., and Lester, J.N. 1995. The value of salt marsh as a sea defence. Mar. Pollut. Bull. 30: 180-189. doi: 10.1016| 0025-326X(94)00173-7.

Kirwan, M.L., and Murray, A.B. 2007. A coupled geomorphic and ecological model of tidal marsh evolution. Proc. Natl. Acad. Sci. USA, 104: 6118-6122. doi: 10.1073/pnas.0700958104. PMID: 17389384.

Krolik-Root, C., Stansbury, D.L., and Burnside, N.G. 2015. Effective LiDAR-based modelling and visualisation of managed retreat scenarios for coastal planning: An example from the southern UK. Ocean Coast. Manag. 114: $164-174$. doi: 10.1016/j.ocecoaman.2015.06.013.

Liu, Y.B. 2012. Prediction methods to determine stability of dam if there is piping. IERI Procedia, 1: 131-137. doi: 10.1016/j.ieri.2012.06.021.

Marani, M., Lanzoni, S., Zandolin, D., Seminara, G., and Rinaldo, A. 2002. Tidal meanders. Water Resour. Res. 38: 7-1-7-14. doi: 10.1029/2001WR000404.

Marani, M., Belluco, E., D’Alpaos, A., Defina, A., Lanzoni, S., and Rinaldo, A. 2003. On the drainage density of tidal networks. Water Resour. Res. 39: 1040. doi: 10.1029/2001WR001051.

Mazik, K., Musk, W., Dawes, O., Solyanko, K., Brown, S., Mander, L., and Elliott, M. 2010. Managed realignment as compensation for the loss of intertidal mudflat: A short term solution to a long term problem? Estuar. Coast. Shelf Sci. 90: 11-20. doi: 10.1016/j.ecss.2010.07.009.

Millard, K., Redden, A.M., Webster, T., and Stewart, H. 2013. Use of GIS and high resolution LiDAR in salt marsh restoration site suitability assessments in the upper Bay of Fundy, Canada. Wetlands Ecol. Manage. 21: 243-262. doi: 10.1007/s11273-013-9303-9.

Moller, I., Kudella, M., Rupprecht, F., Spencer, T., Paul, M., van Wesenbeeck, B.K., et al. 2014. Wave attenuation over coastal salt marshes under storm surge conditions. Nat. Geosci. 7: 727-731. doi: 10.1038/ngeo2251.

Mossman, H.L., Brown, M.J.H., Davy, A.J., and Grant, A. 2012. Constraints on salt marsh development following managed coastal realignment: Dispersal limitation or environmental tolerance? Restor. Ecol. 20: 65-75. doi: 10.1111/j.1526-100X.2010.00745.x.

Ni, W., Wang, Y.P., Symonds, A.M., and Collins, M.B. 2014. Intertidal flat development in response to controlled embankment retreat: Freiston Shore, The Wash, UK. Mar. Geol. 355: 260-273. doi: 10.1016/j.margeo.2014.06.001.

Nolan, M., Larsen, C., and Sturm, M. 2015. Mapping snow depth from manned aircraft on landscape scales at centimeter resolution using structure-from-motion photogrammetry. Cryosphere, 9: 1445-1463. doi: 10.5194/ tc-9-1445-2015.

Pearce, J., Khan, S., and Lewis, P. 2012. Medmerry managed realignment - Sustainable coastal management to gain multiple benefits. In Innovative coastal zone management: Sustainable engineering for a dynamic coast. Edited by A. Schofield. ICE Publishing, London, UK. pp. 243-252.

Pendleton, L., Donato, D.C., Murray, B.C., Crooks, S., Jenkins, W.A., Sifleet, S., et al. 2012. Estimating global "blue carbon" emissions from conversion and degradation of vegetated coastal ecosystems. PLoS ONE, 7: e43542. doi: 10.1371/journal.pone.0043542. PMID: 22962585.

Rotman, R., Naylor, L., McDonnell, R., and MacNiocaill, C. 2008. Sediment transport on the Freiston Shore managed realignment site: An investigation using environmental magnetism. Geomorphology, 100: 241-255. doi: 10.1016/j. geomorph.2007.12.006.

Spencer, K.L., and Harvey, G.L. 2012. Understanding system disturbance and ecosystem services in restored saltmarshes: Integrating physical and biogeochemical processes. Estuar. Coast. Shelf Sci. 106: 23-32. doi: 10.1016/j. ecss.2012.04.020.

Spencer, K.L., Carr, S.J., Diggens, L.M., Tempest, J.A., Morris, M.A., and Harvey, G.L. 2017. The impact of prerestoration land-use and disturbance on sediment structure, hydrology and the sediment geochemical 
environment in restored saltmarshes. Sci. Total Environ. 587-588: 47-58. doi: 10.1016/j.scitotenv.2016.11.032. PMID: 29494968.

Strong, C.J., Burnside, N.G., and Llewellyn, D. 2017. The potential of small-Unmanned Aircraft Systems for the rapid detection of threatened unimproved grassland communities using an Enhanced Normalized Difference Vegetation Index. PLoS ONE, 12: e0186193. doi: 10.1371/journal.pone.0186193. PMID: 29023504.

Symonds, A.M., and Collins, M.B. 2007. The establishment and degeneration of a temporary creek system in response to managed coastal realignment: The Wash, UK. Earth Surf. Processes Landforms, 32: 1783-1796. doi: 10.1002/esp.1495.

Tempest, J.A., Harvey, G.L., and Spencer, K.L. 2015. Modified sediments and subsurface hydrology in natural and recreated salt marshes and implications for delivery of ecosystem services. Hydrol. Process. 29: 2346-2357. doi: 10.1002/hyp.10368.

Tonkin, T.N., and Midgley, N.G. 2016. Ground-control networks for image based surface reconstruction: An investigation of optimum survey designs using UAV derived imagery and structure-from-motion photogrammetry. Remote Sens. 8: 786. doi: 10.3390/rs8090786.

Vandenbruwaene, W., Meire, P., and Temmerman, S. 2012. Formation and evolution of a tidal channel network within a constructed tidal marsh. Geomorphology, 151: 114-125. doi: 10.1016/j.geomorph.2012.01.022.

Wang, S., Chen, J.-S., He, H.-Q., and He, W.-Z. 2016. Experimental study on piping in sandy gravel foundations considering effect of overlying clay. Water Sci. Eng. 9: 165-171. doi: 10.1016/j.wse.2016.06.001.

Watts, C.W., Tolhurst, T.J., Black, K.S., and Whitmore, A.P. 2003. In situ measurements of erosion shear stress and geotechnical shear strength of the intertidal sediments of the experimental managed realignment scheme at Tollesbury, Essex, UK. Estuar. Coast. Shelf Sci. 58: 611-620. doi: 10.1016/S0272-7714(03)00139-2.

Westoby, M.J., Brasington, J., Glasser, N.F., Hambrey, M.J., and Reynolds, J.M. 2012. 'Structure-from-Motion' photogrammetry: A low-cost, effective tool for geoscience applications. Geomorphology, 179: 300-314. doi: 10.1016/j. geomorph.2012.08.021.

Whitehouse, R.J.S., Bassoullet, P., Dyer, K.R., Mitchener, H.J., and Roberts, W. 2000. The influence of bedforms on flow and sediment transport over intertidal mudflats. Cont. Shelf Res. 20: 1099-1124. doi: 10.1016/S0278-4343(00) 00014-5.

Williams, P.B., Orr, M.K., and Garrity, N.J. 2002. Hydraulic geometry: A geomorphic design tool for tidal marsh channel evolution in wetland restoration projects. Restor. Ecol. 10: 577-590. doi: 10.1046/j.1526-100X.2002. t01-1-02035.x. 